\title{
A Study on Prevalence of Hypertension among Adults Aged 20- 70 Years in Vencode, Kerala, India
}

\section{P S Sreejith $* 1$, V.S.Kirankumar ${ }^{2}$.}

${ }^{* 1}$ Associate Professor,Department of Community Medicine, SUT Academy of Medical Sciences, Thiruvananthapuram, Kerala, India

2 Assistant Professor,Department of Infectious Diseases, Govt.Medical College, Thiruvananthapuram, Kerala, India.

\section{ABSTRACT}

Background: Chronic non communicable diseases are important among the adult population all over the world. The prevalence of chronic diseases like diabetes mellitus and hypertension is showing an upward trend. Objective: To measure the prevalence of hypertension and identify the risk factors.

Materials and Methods: A cross sectional study was conducted among adults aged 20-70 years residing in Vencode (Nedumangad M unicipality) during the study period of two months by using predesigned, pre-tested and structured schedule. By using systematic sampling method, 100 individuals were selected and studied. Data entry was made using SPSS

Results: The study showed that $44 \%$ of the sample were hypertensives. In our study group $37 \%$ were males and $63 \%$ were females. The age group ranged between $20-70$ years. M ost of them belonged to the age group between $40-50$ years. $54 \%$ of the individuals showed a positive family history. Statistically significant association was found between family history, increasing age and hypertension.

Conclusion: The study showed that $44 \%$ of the sample were hypertensives. Significant statistical association with hypertension has been obtained for family history and increasing age. No statistically significant association was obtained for other variables.

KEY W ORDS: Prevalence, Hypertension, Adults.

Address for correspondence: Dr. P S Sreejith Associate Professor,Department of Community Medicine, SUT Academy of M edical Sciences,Thiruvananthapuram, Kerala. India.

Mobile no.: +919847145987 E-Mail: 8college4@gmail.com

\begin{tabular}{|c|c|c|}
\hline \multicolumn{3}{|c|}{ Online Access and Article Informtaion } \\
\hline \multirow{2}{*}{ 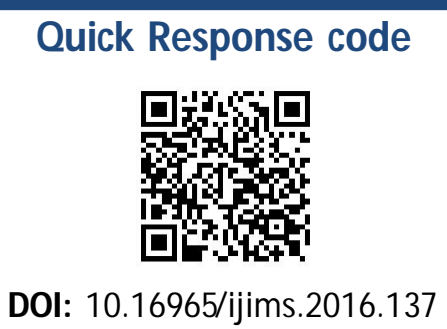 } & \multicolumn{2}{|c|}{$\begin{array}{l}\text { International Journal of Integrative Medical Sciences } \\
\qquad \text { www.imedsciences.com }\end{array}$} \\
\hline & $\begin{array}{l}\text { Received: 29-06-2016 } \\
\text { Reviewed: 29-06-2016 }\end{array}$ & $\begin{array}{l}\text { Accepted: 19-07-2016 } \\
\text { Published: 31-07-2016 }\end{array}$ \\
\hline Source of Funding: Self & & interest: None \\
\hline
\end{tabular}

\section{INTRODUCTION}

Hypertension has been identified as one of the risk factors for cardiovascular morbidity and mortality [1]. Hypertension prevalence is increasing in all the countries and the rate of increase depends on the epidemiological transition the country is passing through [1]. It is an acute condition of concern due to its role in Coronary artery disease and other vascular complications [2]. The prevalence pattern of hypertension in developed countries is different from that in developing countries [2]. Community surveys have documented that between $2 n d$ and 6 th decade prevalence of hypertension has increased by 30 times among urban dwellers and by 10 times among rural inhabitants [2]. Various factors have contributed to this major trend and may be due to changing life style, obesity, behaviour pattern of the people etc [2]. Present study was undertaken to measure the prevalence of hypertension and to identify the risk factors responsible with reference to 
medical, social and individual characteristics, with a view to formulate preventive measures, especially applicable to rural population in Vencode, Kerala, India.

Objective of the present study aimed to calculate the prevalence of hypertension among adults aged 20-70 years in Vencode, kerala, India and also to find out the association between various risk factors and hypertension

Review of literature: Sushil K.Bansal, Sunil D.Kandpal, William K.Gray, Richard W.Walker, and Deepak Goel conducted a study on The prevalence of hypertension and hypertension risk factors in a rural India community and their inference was that therates of hypertension in the rural community under study are similar to those seen in high-income countries and in urban India.M eshram,N Arlappa,N Baalkrishna,KM Rao,A Laxmaiah,GNV Brahmam studied the prevalence of hypertension, its correlates and awareness among adult tribal population of Kerala state,India and opined that of the 4,193 adults of $\geq 20$ years of age covered, $1,641(40 \%)$ were classified as hypertensive. M.C. kalavathy, K.R.Thankappan, P.SankaraSarma, R.S.Vasan conducted a study on prevalence, awareness, treatment and control of hypertension in an elderly community-based sample in Kerala,India and concluded that there is association between the various risk factors and hypertension.

\section{MATERIALS AND METHODS}

Study Design: Cross-sectional study.

Study Setting: The study was conducted among hundred individuals of age group 20-70 years residing in Ward VI of Nedumangad M unicipality. The total population was 1222 and it included 569 males and 653 females, according to Census, 2011.

Study Period: Two months (September-october, 2014)

Study Tools Questionnaire and Sphygmomanometer.

Questionnaire: The following information was collected from each subject through a validated questionnaire administered by the volunteers: age, Sex, occupation, Income status, weight, height, Pattern of salt intake, Dietary pattern, past history of any examination of blood pressure and hypertension, or any of its complications, Pattern of physical activity and addictions.

Blood pressure measurement: Questionnaires were administered for each participant. After verifying the questionnaires, blood pressure was measured using the auscultatory method with a standardized calibrated mercury column type of sphygmomanometer and an appropriate sized cuff encircling at least eighty percent of the left arm in the seated posture, with feet on the floor and arm supported at the heart level. Following a standardized protocol, two separate measurements were recorded and an average of the two measurements after proper rest and due explanation to the examined participant about objective of the study. In some cases were high blood pressure was recorded, for the first time, readings were taken twice and took the average of two close readings. Systolic BP is the point at which the first of two or more sounds is heard (phase I) and diastolic BP is the point before the disappearance of sounds (Phase V). Salt intake was assessed from the amount of salt used in cooking and extra alt used during meals.

Sampling Method and Sample Size: The sampling method used is systematic Random sampling method. This was done by picking the 10th unit regular intervals, the houses were numbered first. Then a number was selected at random between 1 to 10.Then every 10 th number from that point was selected. By this method,each unit in the sampling frame would have the same chance of being selected, but the number of possible samples is greatly reduced. The sample size was 100 individuals of the group 20-70 years.

Data Analysis: Method of data analysis was done using SPSS software. Version between the two gender groups in relationship to different stages of hypertension and normal individuals, by using appropriate test of significance (Chi square) with $95 \%$ confidence level and $p \varangle 0.05$ level. In case of associated risk factor, subgroup analysis was done for different groups like increasing age, smoking, alcohol use, salt consumption, physical inactivity etc. 


\section{RESULTS AND DISCUSSION}

It has been observed from the table that the prevalence of hypertension was greater among age groups $40-50$ years and $60-70$ years. Greater prevalence of hypertension was found among those with a positive family history than with no family history. The risk factors age and family history have shown a significant association statistically with hypertension. With control of communicable disease and increased life expectancy with lifestyle changes,

Table 1: Showing preparation of studying population.

\begin{tabular}{|c|c|c|}
\hline Variable & Category & Frequency \\
\hline \multirow{5}{*}{ Age (years) } & $20-30$ & 24 \\
\hline & $30-40$ & 17 \\
\hline & $40-50$ & 25 \\
\hline & $50-60$ & 17 \\
\hline & $60-70$ & 17 \\
\hline \multirow{2}{*}{ Sex } & Males & 37 \\
\hline & Females & 63 \\
\hline \multirow{2}{*}{ Family history } & Present & 54 \\
\hline & Absent & 46 \\
\hline \multirow{2}{*}{ Smoking } & Smokers & 19 \\
\hline & Non smokers & 81 \\
\hline \multirow[b]{2}{*}{ Alcohol } & Alcoholics & 12 \\
\hline & $\begin{array}{c}\text { Non } \\
\text { alcoholics } \\
\end{array}$ & 88 \\
\hline \multirow{3}{*}{ Physical activity } & Mild & 56 \\
\hline & Moderate & 25 \\
\hline & Good & 19 \\
\hline \multirow{2}{*}{ Salt consumption } & Heavy & 31 \\
\hline & Normal & 69 \\
\hline
\end{tabular}

Table 2: Association between hypertension and study variables.

\begin{tabular}{|c|c|c|c|c|c|c|}
\hline \multirow{2}{*}{ Variable } & \multirow{2}{*}{ Category } & \multicolumn{2}{|c|}{ Hypertensives } & \multicolumn{2}{|c|}{ Non Hypertensives } & \multirow{2}{*}{ Pvalue } \\
\hline & & Freq & $\%$ & Freq & $\%$ & \\
\hline \multirow{5}{*}{ Age } & $20-30$ & 1 & 2.3 & 24 & 41.1 & \multirow{5}{*}{0.014} \\
\hline & $30-40$ & 3 & 6.8 & 14 & 25 & \\
\hline & $40-50$ & 16 & 36.6 & 9 & 16.1 & \\
\hline & $50-60$ & 11 & 25 & 6 & 10.6 & \\
\hline & $60-70$ & 13 & 29.5 & 4 & 7.1 & \\
\hline \multirow{2}{*}{ Sex } & Male & 17 & 38.6 & 20 & 35.7 & \multirow{2}{*}{0.836} \\
\hline & Female & 27 & 61.4 & 36 & 64.3 & \\
\hline \multirow{2}{*}{ Family history } & Present & 29 & 65.9 & 25 & 44.6 & \multirow{2}{*}{0.044} \\
\hline & Absent & 15 & 34.1 & 31 & 55.4 & \\
\hline \multirow{2}{*}{ Smoking } & Smokers & 9 & 20.5 & 10 & 17.1 & \multirow{2}{*}{0.801} \\
\hline & Non smokers & 35 & 79.5 & 46 & 82.1 & \\
\hline \multirow[b]{2}{*}{ Alcohol } & Alcoholics & 8 & 18.1 & 4 & 7.4 & \multirow[b]{2}{*}{0.124} \\
\hline & $\begin{array}{c}\text { Non } \\
\text { alcoholics }\end{array}$ & 36 & 81.8 & 52 & 92.9 & \\
\hline \multirow{2}{*}{ Diet } & $\begin{array}{c}\text { Heavy salt } \\
\text { intake }\end{array}$ & 15 & 34.1 & 16 & 28.6 & \multirow{2}{*}{0.664} \\
\hline & $\begin{array}{c}\text { Normal salt } \\
\text { intake }\end{array}$ & 29 & 65.9 & 40 & 71.4 & \\
\hline \multirow{3}{*}{ Physical activity } & Mild & 24 & 54.5 & 32 & 57.1 & \multirow{3}{*}{0.584} \\
\hline & Moderate & 13 & 29.5 & 12 & 21.4 & \\
\hline & Good & 7 & 15.9 & 12 & 21.4 & \\
\hline
\end{tabular}

hypertension is becoming one of the emergency problems with its implications for concomitant increase in risk of cardiovascular and renal disease. In the present study, out of 100 individuals examined, 44 individuals were found to be suffering from $\mathrm{HT}$ and overall prevalence rate of HT was found to be $44 \%$ among both sexes. However the prevalence of HT was $38.6 \%$ among males and $51.4 \%$ among females.

\section{CONCLUSION}

The study showed that 44 individuals were hypertensives. Significant statistical association has been obtained for family history and increasing age. No statistically significant association was obtained for other study variables.

\section{REFERENCES}

[1]. Agarwal AK, Yunus M, Khan A, Ahmad J. A clinicalepidemiological study of hypertension in rural population of Jawan Block, Distt, Aligarh (UP) India.J R Soc Health. 1994 Feb;114(1):17-9.

[2]. Ahlawat SK, Singh M M , Kumar R, Kumari S, Sharma BK Time trends in the prevalence of hypertension and associated risk factors in Chandigarh.J Indian Med Assoc. 2002 Sep;100(9):547-52,554-5,572.

[3]. Ahuja MMS. Epidemiological studies on diabetes mellitus in India. In: Epidemiology of diabetes in developing countries. Ahuja MMS, Ed. New Delhi, Interprint, 1979:29-38.

[4]. Bai PVA, M urthi BN, Chellamariayappan M, Gupte MD, Krishnaswami CV. Prevalence of known diabetes in Chennai City.J Assoc Physicians India. 2001 Oct;49:974-81.

[5]. Baldwa VS et al. Prevalence of hypertension in a rural community of Rajastan. J Assoc Physicians Ind 1984;32:1042-47.

[6]. Barrington $H$, Abraham KA, Hill PG, Kanagasaba pathy AS, Cherian G. Serum lipids and lipoproteins in control subjects and patients with ishaemic heart disease. J Assoc Physicians India 1980; 28: $217-$ 222.

\section{How to cite this article:}

P S Sreejith, V.S.Kirankumar. A Study on Prevalence of Hypertension among Adults Aged 20-70 Years in Vencode, Kerala, India. Int J Intg Med Sci 2016;3(7):350-352. DOI: 10.16965/ijims.2016.137 